\title{
Assessment of Fungal Growth at Hemodialysis and Peritoneal Dialysis Unit in Hawler Teaching Hospital
}

\author{
Vian B. Nehmatullah \\ Dept. of Basic Science, Microbiology Unit, College of Medicine, Hawler Medical University, Erbil, Iraq \\ Email: vianbadr@yahoo.com
}

(Received February 09, 2019; Accepted March 09, 2020; Available online June 01, 2020)

DOI: 10.33899/edusj.2020.126676.1049, (C) 2020, College of Education for Pure Science, University of Mosul.

This is an open access article under the CC BY 4.0 license (http://creativecommons.org/licenses/by/4.0/).

\begin{abstract}
Dialysis is used when the patient's kidneys can no longer perform their functions normally; it is a treatment that performs the functions of natural kidneys. Most patients begin dialysis when their kidneys have lost $85-90 \%$ of their ability to work naturally and they have to depend on dialysis for the rest of their lives, is called end -stage renal disease (ESRD). Infection in patients with end stage renal disease (ESRD) is usually treated with hemodialysis (HD) or peritoneal dialysis (PD). End stage renal disease a major cause of morbidity and mortality, in order to assess the fungal growth at hemodialysis and peritoneal dialysis unit a descriptive study was conducted at hemodialysis and peritoneal dialysis units in Hawler teaching hospital, from $15^{\text {th }}$ of January to the end of May 2017;the study also includes the access sites and peritoneal catheter site. Factors that affected the access site among dialysis patient in the hospital. Sample of 63 patients, who were attending to the dialysis unit at time of the data collection, had been taken; in addition to that swab samples had been gathered from access site and peritoneal catheter site. The results of the study revealed that the fungal growth was positive at dialysis access sites, where the total percentage was $84.1 \%$ and that of peritoneal catheter site was $15.85 \%$. In these unites, different types of filamentous fungi and yeasts had been successfully isolated.
\end{abstract}

Keywords: Fungi, Hemodialysis, Dialysis Unit, peritoneal dialysis.

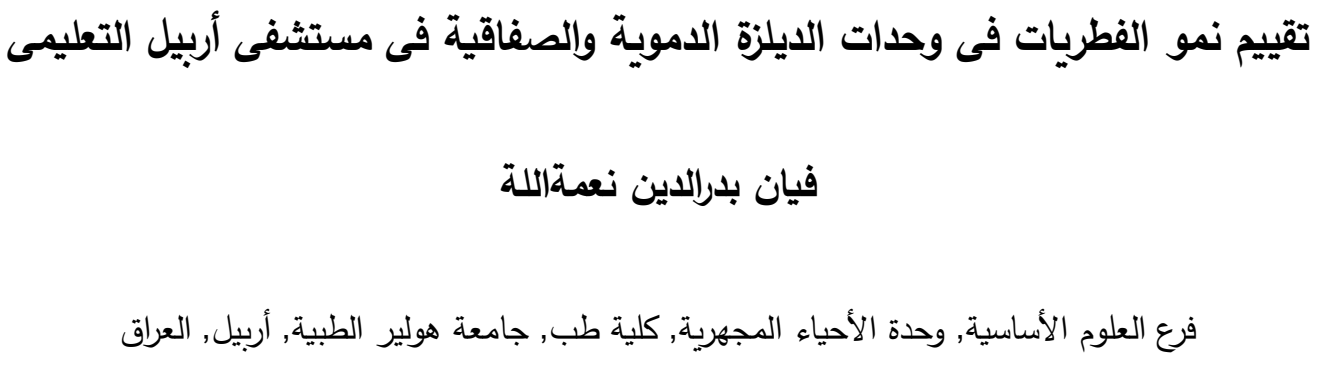

الخلاصة

عندما تقشل الكلى، فإن الغسيل الكلوي هو العلاج و يؤدي وظائف الكلى الطبيعية. يبدأ معظم المرضى بغسيل الكلى عندما تفقد الكلى 85-90 ٪ من قدرتها على العمل وسيستمرون في مراجعة و حدة غسيل الكلى لبقية حياتهم، وهذا ما يسمى الى مرض مرحلة نهاية الكلى (ESRD) . المرضى الذين يعانون من مرض مرحلة نهاية الكلى (ESRD) يتم غسيل الكلى (HD) 


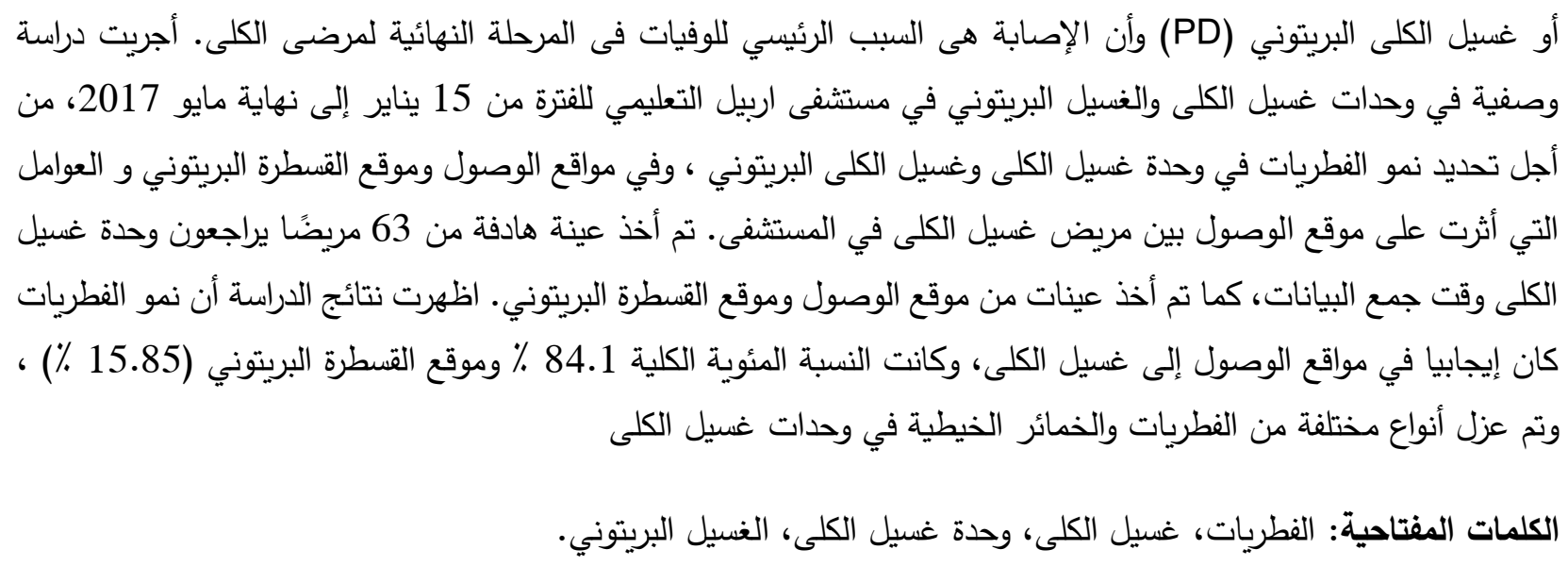

\section{Introduction:}

Patients who suffer from kidneys fail are exposed to 1800-36000 liter of water during the dialysis in each year (1).Patients with end-stage renal disease (ESRD) widely used Peritoneal dialysis (PD) and renal replacement therapy at home (2). Dialysis equipment contaminated with high levels of microorganisms, several natural inhabitants of water and soil found as saprophytic fungi act as parasite (pathogens) in immunocomptent host. Patients with hemodialysis are immunosuppressed; this makes them highly susceptible to infection, and they require frequent hospitalization and surgery, which ultimately increase their opportunities for exposure to nosocomial infections. The most frequent infections with fungal are those with involving vascular access (3).

Hemodialysis patients' poor personal hygiene is a risk factor for their susceptibility to infection especially patients with vascular access site. Therefore these patients should be taught how to improve and maintain their personal hygiene. Fungal exit-site infections are more frequent than peritonitis, but they more easily resolved, although they may potentiate the development of a subsequent peritonitis . Fungal infections are primarily caused by opportunistic fungal pathogens, such as Candida species that causes diseases and proliferate in the human host as a result of locally or systemically debilitated immune system (4).

Microorganisms grow on tanks and taps. Suitable sites for biofilm formations are on tanks and tubes (3).Water is usually distributed in PVC pipes throughout the entire water system. As a result, microbial materials are transported by water to the dialysis machines. Dialysate fluids, which are used for dialysis, remain non-sterile and can be easily contaminated by several fungi (5). Several saprophytic fungi such as (Candida parapsilosis Trichoderma, Chrysosporium, Cladosporium, Fusarium, Verticillium, Acremonium, Penicillum, and Aspergillus) were isolated from hemodialysis centers water.(6,7) . 


\section{Materials and methods}

\section{I-Design of the study:}

The descriptive design was adapted in Hawler Teaching Hospital on 15 January 2017 till the end of May 2017 in order to assess prevalence of fungal growth in hemodialysis and peritoneal dialysis unit, and also in access and peritoneal catheter sites.

\section{II -The setting of the study:}

The study is carried out at Hawler Teaching Hospital,

\section{III -Population and Sample of the study:}

The population consists of a purposive sample of 63 patients who were attending the dialysis unit at time of the data collection, and also swabs samples gathered from Hawler dialysis units access site and peritoneal catheter site. All of these samples were taken from the patient who were admitted to the dialysis for treatment at time of data collection.

\section{IV-Instrument construction:}

To a chief the aim of the study a questionnaire which is of two main domains are used. The first domains conserving the factors that affected fungal growth in dialysis site, while the second domain focus on the factors that affect care of the access site among dialysis patients. Swabs samples taken from dialysis unit, access site and peritoneal catheter site had been studied; also environmental swabs that were gathered from Hawler dialysis units had been examined.

\section{V-Sample collection:}

Swabs were used to obtain the specimens; these swabs were immediately transferred from the unit to the laboratory for culturing in Sabouraud dextrose agar (SDA), that was enriched with cycloheximide and chloramphenicol (30 mg / $100 \mathrm{ml})$; these samples had been incubated two weeks at $30^{\circ} \mathrm{C}$ and examined daily for identification of growing colonies.

\section{VI -Organism identification:}

A traditional method was used for identification procedure of filamentous fungi by both macroscopic feature and microscopic examination $(8,9)$.Germ tube test was used for identification of yeast as physiological tests ; carbohydrate assimilation test (API 20C AUX ) was used as biochemical test and Corn meal agar also used for morphological identification .

\section{Results:}

Table (1) shows environmental swabs related to dialysis units. Fungal growth was presented with all environmental swabs in dialysis environments. As it is shown in this table ,many types of fungi are isolated ; they belongs to filamentous fungi (molds) and yeasts, such as Aspergillus niger ,penicillium spp. ,Rhizopus spp., Cladiosporium spp. and Fusarium spp.,Candida albicans ,Candida glabrata and Candida parapsillosis that belongs to yeast type. 
Table (1) Fungi isolated from environment of dialysis units

\begin{tabular}{|l|l|}
\hline \multicolumn{1}{|c|}{ Sources of Samples } & \multicolumn{1}{c|}{ Isolated Fungi } \\
\hline Air & Aspergillus niger, Rhizopus spp. \\
\hline Floor & Cladosporium spp. , Candida albicans \\
\hline Walls & Aspergillus terreus, Penicillium spp. \\
\hline Dialysis beds & Rhizopus spp. \\
\hline Dialysis trays & Trichoderma spp. \\
\hline Surgical instruments & Candida parapsillosis \\
\hline Staff's nasal & Candida albicans \\
\hline Staff's hands & Candida glabrata \\
\hline Shoes & Aspergillus niger, Cladosporium spp \\
\hline Gloves & Penicillium spp. \\
\hline Cuff of sphygmomanometers & Candida paraosillosis \\
\hline Dialysis machine & Rhizopus spp. \\
\hline Isolation room floor & Fusarium spp. ,Candida albicans \\
\hline Skin & Candida albicans \\
\hline
\end{tabular}

Table (2) shows that (38.1) of fungal growth were presented from access and peritoneal catheter site. Fungal growth from peritoneal catheter site was (50\%), and the commonest fungi isolated were Candida parapsilosis and C.albicans in fistula site; C.glabrata and Aspergillus niger in peritoneal catheter site. The study revealed that $(60.31 \%)$ of fungal growth was with C.parapsilosis and C. albicans.

The results of figure (1) show that the highest percentages of fungal growth was $60.31 \%$ registered in fistula site and the lowest percentages of fungal growth was $7.93 \%$ that was registered in shunt site, jugular vein site and femoral vein site which. While percentages of fungal species show in figure (2) were $C$. parapsillosis and $C$. albicans represent the highest species which was (60.31\%) while C. glabrata and Aspergillus niger was $(15.87 \%)$ and the lowest percentage that belongs to C. tropicalis, C. albicans and Rhodotoruolla was (7.93\%) .

Table (2) Prevalence of fungal growth at Access Site and Peritoneal Catheter Site 


\begin{tabular}{|c|c|c|c|c|c|c|c|c|}
\hline \multicolumn{9}{|c|}{ Fungal growth } \\
\hline \multirow{2}{*}{\multicolumn{2}{|c|}{ Swab Culture Site }} & \multicolumn{2}{|l|}{ 它 } & \multicolumn{2}{|l|}{ 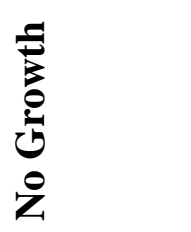 } & \multicolumn{2}{|l|}{ } & \multirow[t]{2}{*}{ Isolated Fungi } \\
\hline & & $\mathbf{F}$ & $\%$ & $\mathbf{F}$ & $\%$ & $\mathbf{F}$ & $\%$ & \\
\hline \multirow{4}{*}{ 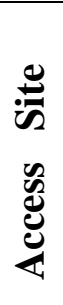 } & Fistula & 13 & 34.2 & 25 & 65.8 & 38 & 60.31 & Candida parapsilosis, C.albicans \\
\hline & Shunt & 2 & 40.0 & 3 & 60.0 & 5 & 7.93 & Candida tropicalis \\
\hline & Jugular Vein & 2 & 40.0 & 3 & 60.0 & 5 & 7.93 & Candida albicans \\
\hline & Femoral vein & 2 & 40.0 & 3 & 60.0 & 5 & 7.93 & Rhodotoruolla spp. \\
\hline \multicolumn{2}{|c|}{ Peritoneal catheter site } & 5 & 50.0 & 5 & $\mathbf{5 0 . 0}$ & $\mathbf{1 0}$ & $\mathbf{1 5 . 8 7}$ & Candida glabrata,Aspergillus niger. \\
\hline \multicolumn{2}{|c|}{ Total } & 24 & 38.1 & 39 & 61.9 & 63 & 100 & \\
\hline
\end{tabular}

$$
\text { F= Frequency }
$$

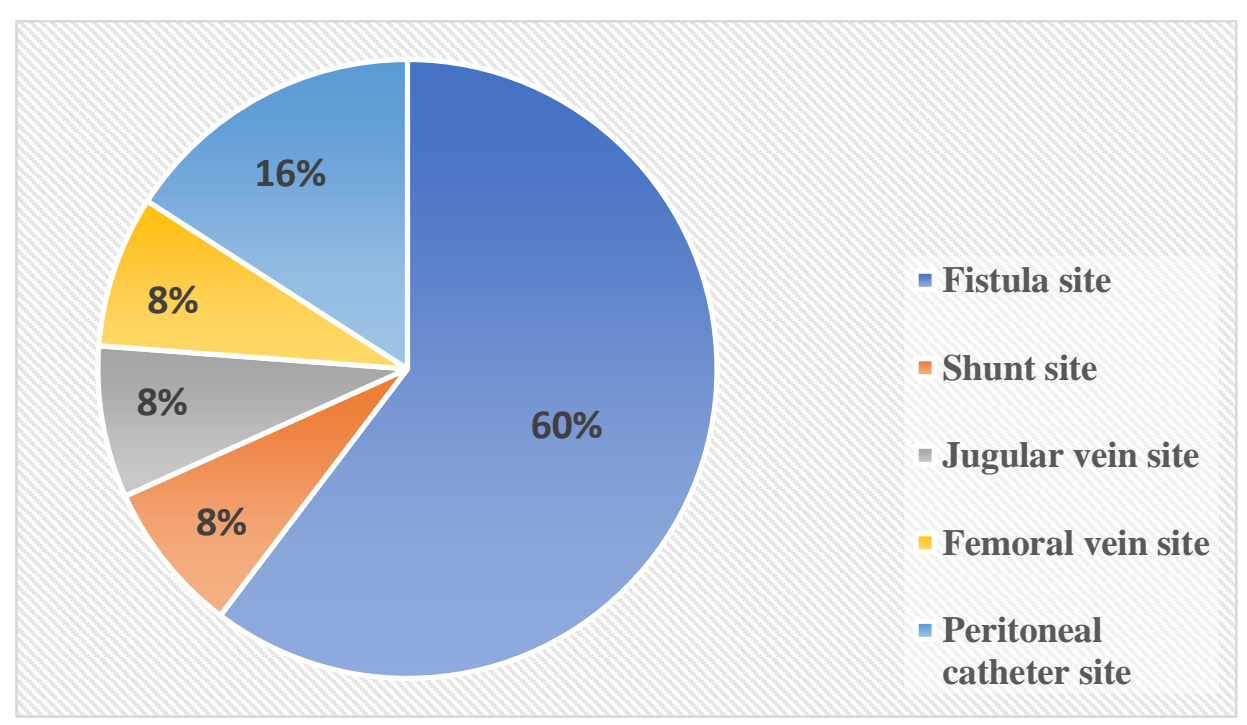

Figure (1) Site of fungal growth 


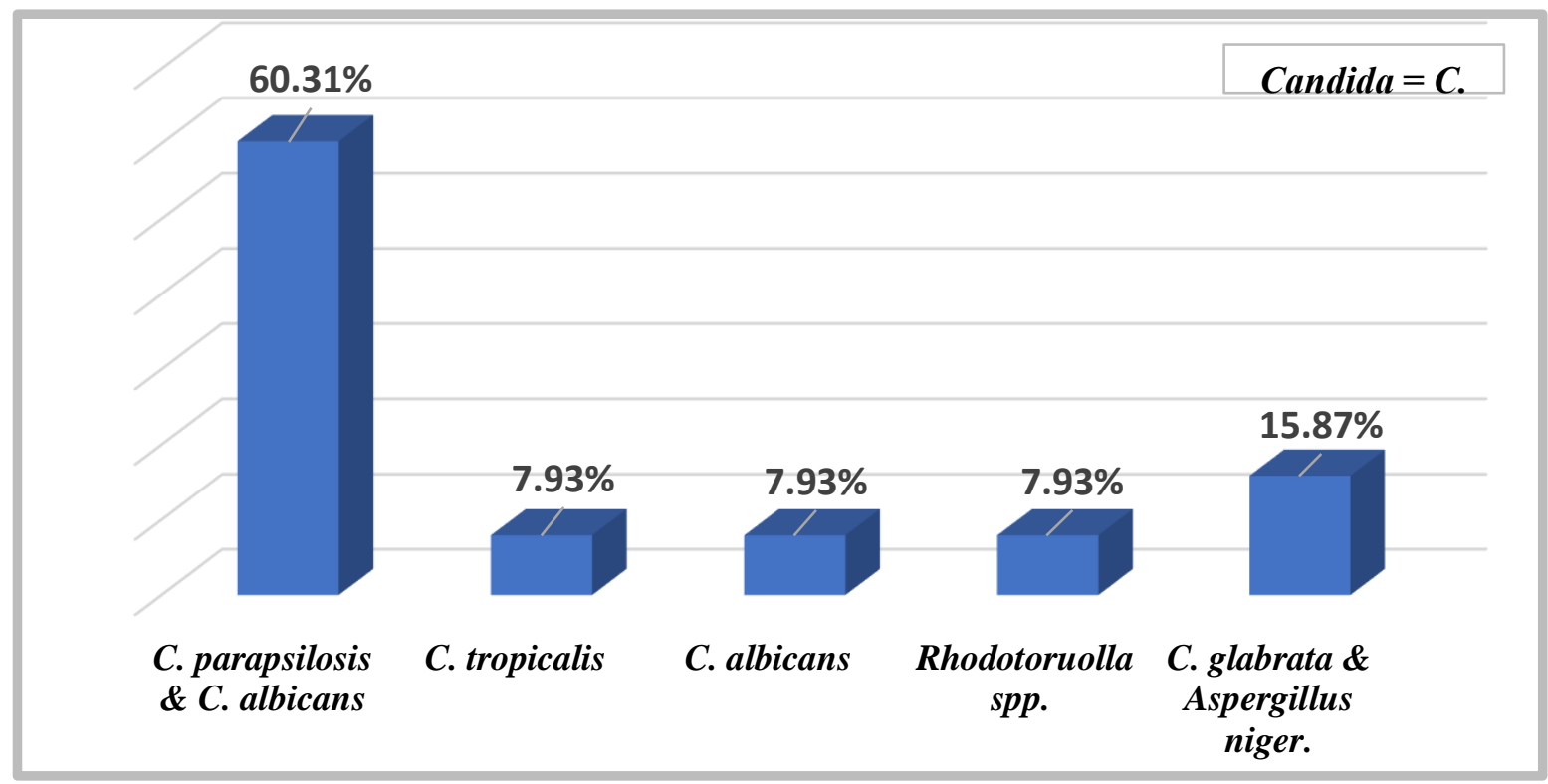

Figure (2) Percentage of fungi isolated from Access site and Peritoneal catheter site

\section{Discussion:}

During hemodialysis process, patients are usually exposed to a lot of water. Risks of fungemia or endotoxemia found as a result of the presence of high concentrations of fungi in water. Contamination of kidney machine is due to presence of high level of fungal elements in outlet water. (10) Solutions consist of glucose and salts have been usually found in outlet water of kidney machine during dialysis procedure. Fluid from dialysis machine provides suitable medium for fast growing of fungi by adding of nitrogen and carbon-containing waste compounds from the patient's blood . In such sample the high concentration of contamination with fungi indicate that outlet water is good media for well growing of fungi (3) .

The results of the current study reveal only $41.43 \%$ of the participants (patients) have fungal growth in the access and peritoneal catheter site (Table 2). This table also shows that fungal growth of peritoneal catheter site was (50\%), and the commonest causative organisms were Candida albicans and C. parapsilosis in fistula site, C. glabrata and Aspergillus niger have been found in peritoneal catheter site, thus this result is near to Goncalves RHP and et al (3) which state that fungi were recovered from $89 \%$ of all water samples collected inside the haemodialysis unit, with prevalence of yeasts in dialysate samples and moulds in tap water samples. Fusarium spp. was the most abundant genus of molds found here in this study, whereas the predominant yeast species was Candida parapsilosis that also agree with Weems (11), who recorded in his study that the high prevalence of $C$. parapsilosis might be due to the ability of the yeast to adhere different surfaces and also the biofilm formation at the end $(12,13)$. Another important factor might be that might be parenteral solutions which used in dialysate promote adherence and growth of $C$. parapsilosis .

This study revealed that $(60.31 \%)$ of fungal growth belongs to Candida spp. this result agrees with Abbott and et al.(14), since they emphasized and demonstrated how patients with maintenance dialysis therapy have defects in their immune system and the risk of instrumentation, which appears 
later become higher specifically in the patients who yield the haemodialysis.Also it is found that the Candida spp. Causes this infection.

Candida spp. accounts for more than (70 \%) of the vascular access site infection; this agrees with (15) they found that a polymicrobial outbreak of peritonitis among patients undergoing intermittent peritoneal dialysis (IPD) treatment attributed to environmental contamination by airborne organisms secondary to hospital renovation. In addition the results reveal that the patients who yield to dialysis are not affected by the outbreak of CAPD. They postulated that organisms with high air counts during the exchange procedure might drop into the connecting system.

Conclusion: This study proves the presence of many fungi in the dialysis unit, especially Candida spp.

Acknowledgment: I would like to thank those who work in the dialysis unit at Hawler Medical Hospital for their constant assistance and the facilitation of sampling they have made to achieve this study.

\section{References:}

1-Montanari LB, Sartori FG, Oliveira Cardoso MJ, Varo SD, Pires RH, Leite CQF, et al., 2009 .Rev Inst Med Trop S Paulo. 51 :37-43.

2--Liliana Simões-Silva, Sara Silva, Carla Santos-Araujo, Joana Sousa, Manuel Pestana, Ricardo Araujo, Isabel Soares-Silva, and Benedita Sampaio-Maia., 2017.Diseases and Medical Microbiol., Article ID 4846363, 7 p .

3- Goncalves RHP, Sartori FG, Montanari LB, Zaia JE, Melhem MSC, Mendes-Giannini MJS, et al. (2008).Occurrence of fungi in water used at a hemodialysis center. Lett Appl Microbiol. ;46:542-547.

4- Kleinpeter, Adv., 2004."Successful treatment of Candidain infections in peritoneal dialysis patients: case reports and review of the literature,"Adv. Peritoneal Dialysis.20:58-61.

5- Arvanitidou M, Spaia S, Katsinas C, Pangidis P, Constantinidis T, Katsouyannopoulos V, Vayonas G.1998. Microbiological quality of water and dialysate in all haemodialysis centers of Greece. Nephrol Dial Transplant.13:949-954

6-Varo SD, Martins CH, Cardoso MJ, Sartori FG, Montanari LB, Pires-Goncalves RH.2007. Isolation of filamentous fungi from water used in a hemodialysis unit. Rev Soc Bras Med Trop.40:326-331.

7- Arvanitidou M, Spaia S, Katsinas C, Pangidis P, Constantinidis T, Katsouyannopoulos V, Vayonas G.1998. Microbiological quality of water and dialysate in all haemodialysis centers of Greece. Nephrol Dial Transplant.13:949-954

8- Gams, W. and Bisset, J. 1998 Morphology and identification of Trichoderma. In Trichoderma and Gliocladium, Vol.1. ed. Kubicek, C.P. and Harman, G.E. .Basic Biology, Taxonomy and Genetics, London, UK: Taylor and Francis pp: 3-37. 
9- de Hoog, G.S.; J. Guarro, J. Gene Â, and M.J. Figueras. 2000. M.J . Atlas of Clinical fungi $.2^{\text {nd }}$. ed. Uppsalalaan, The Netherlands: Centraalbureau voor Schimmel .1126pp.

10- Mahmoudabadi,A.Z. ; Zarrin, M.; Shahbazyan,H. and Koshki,M. 2011. Occurrence of fungi in dialysis water system and dialysis solution in dialysis centers in Ahvaz, Iran. Pak J Med Sci : 27 (2):381-391.

11- Weems, J.J., Jr., 1992. Candida parapsilosis: epidemiology, pathogenicity, clinical manifestations, and antimicrobial susceptibility. Clin Infect Dis 14, 756-766.

12- Kuhn, D.M., Chandra, J., Mukherjee, P.K. and Ghannoum, M.A.,2002. Comparison of biofilms formed by Candida albicans and Candida parapsilosis on bioprosthetic surfaces. Infect Immun 70, 887-898.

13- Panagoda, G.J., Ellepola, A.N. and Samaranayake, L.P. ,2001. Adhesion of Candida parapsilosis to epithelial and acrylic surfaces correlates with cell surface hydrophobicity. Mycoses 44, 29-35.

14- Abbott,K.C.; Hypolite, I.;Tveit; D.P.; Hshieh, P.; Cruess, D. and Agodoa, L.Y. ,2001. Hospitalizations for fungal infections after initiation of chronic dialysis in the United States. Nephron, 89, 426-432.

15-Cheng, V.C. ;Lo ,W.K.; Woo,P.C.; Chan,; Cheng,S.W, ; Ho,M.and Yuen,K.Y., 2001. Polymicrobial outbreak of intermittent peritoneal dialysis peritonitis during external wall renovation at a dialysis center. Perit Dial Int.; 21 (3):296-301. 